\title{
The Demographic, Clinical, Radiographic and Bronchoscopic Evaluation of Anthracosis and Anthracofibrosis Cases
}

\author{
Sevda Sener Comert*, Coskun Dogan, Benan Caglayan, Ali Fidan, Nesrin Kiral and Banu Salepci \\ Dr:Lutfi Kirdar Kartal Training and Resarch Hospital, Pulmonary Diseases Department, Istanbul, Turkey
}

\begin{abstract}
Background: The aim of the study was to evaluate the demographic features, clinical findings, radiological and bronchoscopical findings of patients with bronchial anthracosis.

Methods: Among 1541 patients who underwent broncoscopy in our bronchoscopy unit between 2006-2008, 104 patients with anthrocosis were included in this prospective study. The patient's geographical location, occupation, type of fuel used for cooking in the kitchen and for heating in their house, admission complaints, chest x-ray and thorax computed tomography (CT) findings, bronchoscopic images and the accompanying pathological diagnosis were recorded and evaluated.

Results: A total of $104(6.7 \%)$ patients with a mean age of $61.35 \pm 13.34$ years were included in this study; 49 $(47.1 \%)$ of which were female, $55(52.9 \%)$ male.The most common complaints were cough, dyspnea and sputum production in $71.2 \%, 57.7 \%$ and $49.0 \%$ patients, respectively. In $48(46.1 \%)$ patients history of cigarette smoking was found. While in 31 (38.3\%) patients exposure to mineral dust or biomass in their job was observed, $37(45.7 \%)$ patients were housewives. In all of the patients biomass exposure was found because of the fuel used for heating or in kitchens. Regarding geographical location, we found that the majority of the patients (38.5\%) were from Black Sea region located in northern Anatolia. While the most common chest x-ray findings were consolidation $(51.9 \%)$ and fibrosis $(18.3 \%)$, consolidation $(38.5 \%)$ and fibrosis $(36.5 \%)$ were also found to be the leading thorax CT findings. The most common bronchoscopic findings were bilateral anthracosis, stenosis and bronchial torsion $67.3 \%, 40.4 \%$ and $23.1 \%$ patients, respectively. Among the anthracosis patients, with bronchoscopy 11 of them were found to have malignancy and 7 of them tuberculosis.
\end{abstract}

Conclusion: Large scale, country-wide studies should be conducted for the determination of epidemiological data of bronchial anthracosis and anthracofibrosis in our country in which a high rate of biomass exposure is found.

Keywords: Anthracosis; Anthracofibrosis; Bronchoscopy; Biomass exposure

Abbreviations: CT: Computerised Tomography; TB: Tuberculosis

\section{Introduction}

Anthracosis, a form of pneumoconiosis, is most commonly seen in coal workers. Air pollution, biomass smoke and cigarette smoke are also known as the other enviromental factors for anthracosis [1-5]. The term "anthracotic" is usually used to describe coal and other black pigments of which carbon is a major constituent. Characteristically, coal deposits are present as black plaques in the bronchi [6]. The term "bronchial anthracofibrosis" is of fairly recent origin and has come to define a clinical entity with bronchial lumen narrowing and anthracotic pigmentation visible on bronchoscopy. First reported from Korea, it was predominantly seen in non-smoking ladies with a longstanding history of exposure to wood smoke used either for food cooking or heating. The luminal narrowing and anthracotic pigmentation was most commonly observed in the right middle lobe [6-9]. The CT findings have been reported to include smooth bronchostenosis and peribronchial lymph nodes along with peripheral atelectasis $[6,8,9,11]$. Bronchogenic carcinoma and endobronchial tuberculosis (TB) are two main causes of bronchostenosis that can be accompanied by peribronchial nodes and atelectasis $[12,13]$.

Recently, an increasing number of patients in whom dark anthracotic pigmentation in conjunction with bronchial narrowing or obliteration was not associated with environmental exposure to coal dust or smoking, was demonstrated in bronchoscopy patients. This bronchoscopic finding is called "anthracofibrosis". This report is a summary of demographic, clinical, radiographic and bronchoscopic findings of these patient.

\section{Materials and Methods}

Among a total of 1541 patients who underwent bronchoscopy at Dr.Lutfi Kirdar Kartal Research and Training Hospital Pulmonary Diseases Department's Bronchoscopy Unit between 2006-2008, anthracosis and anthracofibrosis were diagnosed in 104 patients. Diagnosis of anthracosis and anthracofibrosis were made solely on the basis of bronchoscopic findings. Patients in whom bronchoscopy revealed definite narrowing or obliteration of lobar or segmental bronchi with anthracotic pigmentation in the surrounding mucosa were considered to have anthracofibrosis and in whom broncoscopy revealed black plaques were considered to have anthracosis and were included in this analysis. Geographical location and proffession of the patients, type of fuel used for heating and cooking in the kitchen, admission complaints, chest X-ray and chest tomography findings, bronchoscopic features and the accompanying diagnosis were evaluated.

The chest CT was performed before bronchoscopy to evaluate lung lesions such as consolidation, athelectasis, mediastinal enlargement or masslike opacities seen on chest radiographs. CT scans were obtained

*Corresponding author: Sevda Sener Comert, Pembe kosk sok. Emek apt. No:16 D:14 Kadikoy Istanbul/Turkey, Tel: 0090216350 5187; Fax: 00902164421884 E-mail: sevdasener2@yahoo.com

Received December 22, 2011; Accepted March 24, 2012; Published March 26 2012

Citation: Comert SS, Dogan C, Caglayan B, Fidan A, Kiral N, et al. (2012) The Demographic, Clinical, Radiographic and Bronchoscopic Evaluation of Anthracosis and Anthracofibrosis Cases. J Pulmonar Respirat Med 2:119. doi:10.4172/2161 105X.1000119

Copyright: @ 2012 Comert SS, et al. This is an open-access article distributed under the terms of the Creative Commons Attribution License, which permits unrestricted use, distribution, and reproduction in any medium, provided the original author and source are credited. 
Citation: Comert SS, Dogan C, Caglayan B, Fidan A, Kiral N, et al. (2012) The Demographic, Clinical, Radiographic and Bronchoscopic Evaluation of Anthracosis and Anthracofibrosis Cases. J Pulmonar Respirat Med 2:119. doi:10.4172/2161-105X.1000119

using Siemens Sensation 4079 CT 57289 spiral multislice CT. CT scans were reported by the same radiologist. This radiologist was not aware of the diagnosis of bronchial anthracofibrosis. The CT analysis included presence or absence and location of consolidation, athelectasis, fibrosis, mediastinal lymph adenopathy and other lesions such as nodule, mass or cavitation.

All patients presented in a manner that raised the suspicion of lung cancer, and all patients had abnormal bronchoscopy findings; however, bronchial washing, brushing and/or, biopsy specimens were taken.

\section{Results}

This group of 104 patients was composed of 55 men and 49 women who ranged in age from 23 to 88 years old (mean 61.35 years). Fifty-six (53.9\%) patients were nonsmokers. In $48(46.1 \%)$ patients history of cigarette smoking was found. While in 31 (38.3\%) patients exposure to mineral dust or biomass in their job was observed, 37 (45.7\%) patients were housewives. In all of the patients biomass exposure was found because of the type of fuel used for heating or in kitchens. Fourty seven patients lived in urban areas and the rest in rural areas. Regarding geographical location, we found that the majority of the patients (38.5\%) were from Black Sea region located in northern Anatolia. Presenting clinical symptoms were cough (71.2\%), dyspnea (57.7\%), sputum (49\%), sweating (48.1\%) and wheezing $(41.3 \%)$ in order of frequency. Nine patients were asymptomatic. These patients were refferred to our hospital because of radiographic abnormality on routine chest radiographic evaluation.

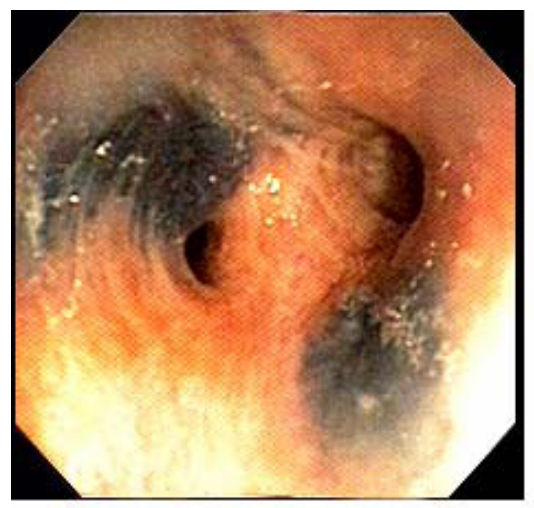

Figure 1: Bilateral anthracosis, stenosis and torsion were the leading bronchoscopic findings.

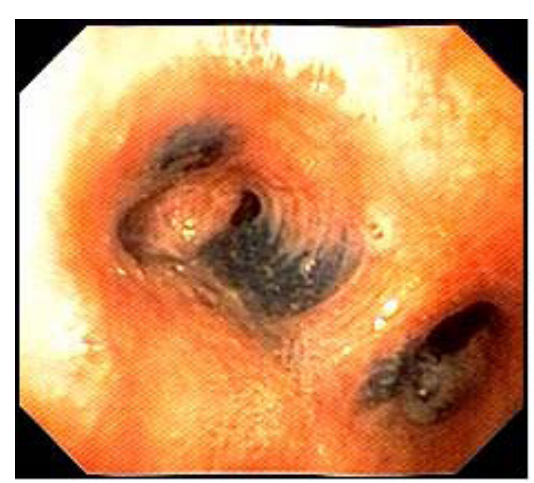

Figure 2: Bilateral anthracosis, stenosis and torsion were the leading bronchoscopic findings.

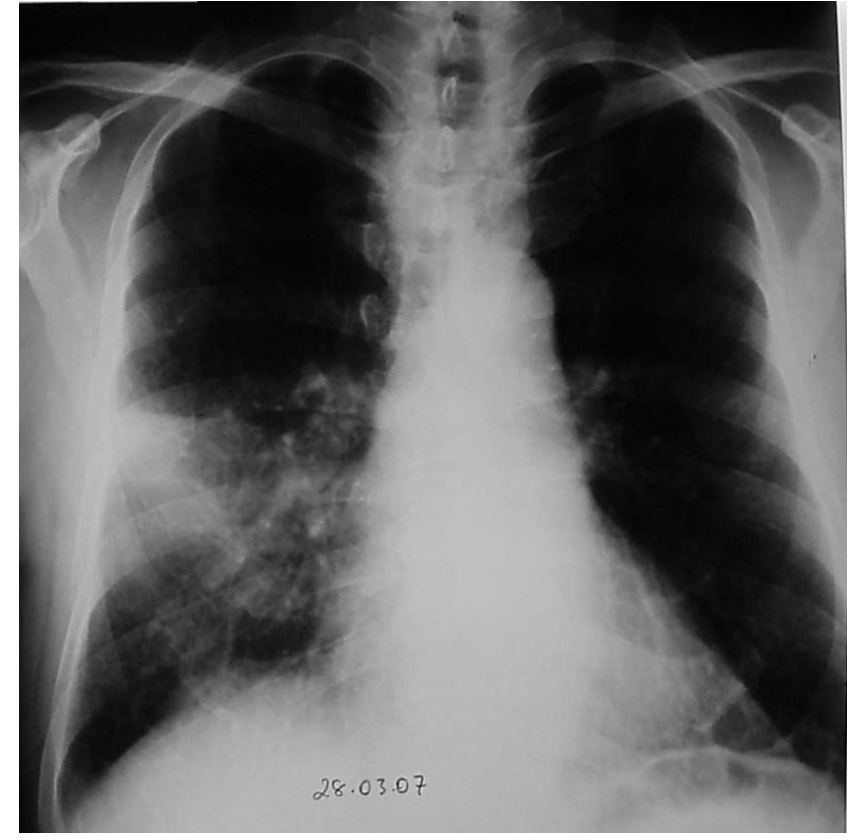

Figure 3: Consolidation was the most frequent chest $\mathrm{X}$-ray finding.

The principal finding of bronchoscopy was anthracotic pigmentation of bronchial mucosa and bronchial luminal narrowing. While both anthracosis and anthracofibrosis were observed in 60 (57.7\%) of these patients, only bronchial anthracotic pigmentation (plaques) were estabilished in $44(42.3 \%)$ of them. Bilateral anthracosis, stenosis and torsion were the leading bronchoscopic findings (Figure 1, Figure 2).

The severity of bronchial narrowing was variable in each bronchus and had no correlation with the degree of anthracotic pigmentation. On bronchoscopy, the left upper lobe bronchus was the most commonly involved site. Single site involvement was noted in 32 (30.8\%) of anthracofibrosis and in $33(31.7 \%)$ of anthracosis patients. Bronchial stenosis or torsion was most commonly in segmental bronchi $(n=46$, $44.2 \%$ ) and the most common bronchial sites were the segment bronchi of left upper lobe, right middle lobe and right upper lobe, respectively.

On chest X-ray, consolidation was observed in $51.9 \%$ and fibrosis in $18.3 \%$ (Figure 3). In thorax CT findings, consolidation $(38.5 \%)$ and fibrosis (36.5\%) were also seen most commonly (Figure 4 ).

Among these 104 patients 11 of them were found to have malignancy. Active tuberculosis was found in 7 patients. Bronchial washing fluid was positive for acid-fast bacilli in these patients.

\section{Discussion}

Anthracofibrosis is a bronchoscopic finding showing dark anthracotic pigmentation on the bronchial mucosa in conjunction with bronchial narrowing or obliteration [8]. Most patients are presented with cough, dyspnea and sputum. Because of their age and chest ragiographic findings, chest CT and bronchoscopy are usually performed to exclude bronchogenic carcinoma.

Anthracofibrosis has been reported mostly from developing countries mainly from Asia and some case reports are rarely described from North America and Europe [9,14]. The prevalence of anthracosis differ widely in studies. Per 1000 bronchoscopy procedures performed, Wynn et al. [15] reported one case of anthracosis. In contrast to Wynn et al, Mirsadraee et al. [14] found anthracosis in $21 \%$ of patients who 


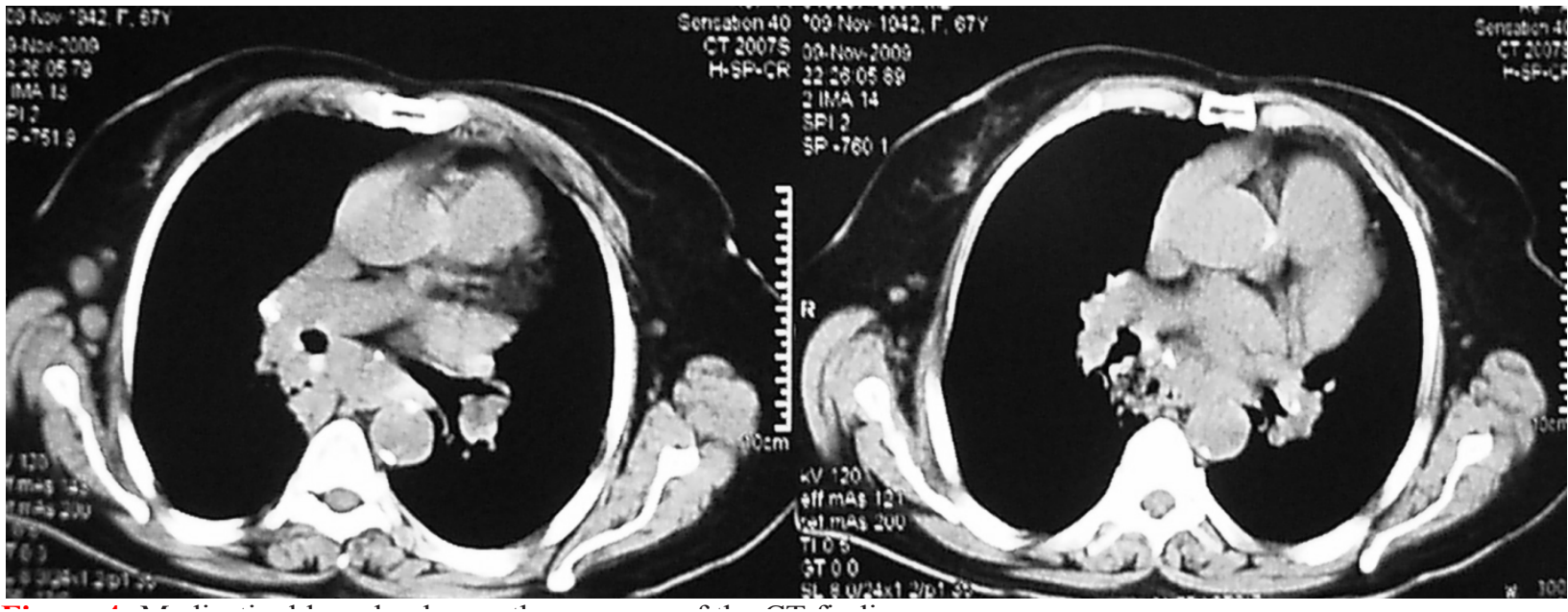

Figure 4: Mediastinal lymph adenopathy was one of the CT findings.

\begin{tabular}{|l|c|}
\hline Female & $49(47.1 \%)$ \\
\hline Male & $55(52.9 \%)$ \\
\hline Age (mean \pm SD) & $61.35 \pm 13.34$ \\
\hline Biomass exposure & $104(100 \%)$ \\
\hline Occupational biomass exposure & $31(38.3 \%)$ \\
\hline Being housewife & $37(45.7 \%)$ \\
\hline Cigarette smoking & $48(46.1 \%)$ \\
\hline
\end{tabular}

Table 1: Demografic properties of patients.

\begin{tabular}{|l|l|l|l|l|l|l|l|}
\hline & RM & RUL & RML & RLL & LM & LUL & LLL \\
\hline Plaque & $13(12.5)$ & $22(21.2)$ & $14(13.5)$ & $15(14.4)$ & $12(11.5)$ & $15(14.4)$ & $18(17.3)$ \\
\hline $\begin{array}{l}\text { Torsion or } \\
\text { stenosis }\end{array}$ & $3(2.9)$ & $25(24.0)$ & $24(23.1)$ & $15(14.4)$ & $1(0.9)$ & $36(34.6)$ & $16(15.4)$ \\
\hline
\end{tabular}

Values given as number (\%)

$\mathrm{RM}$, right main bronchus; RUL, right upper lobar bronchus; RML, right middle lobar bronchus; RLL, right lower lobar bronchus; LM, left main bronchus; LUL, left upper lobar bronchus; LLL, left lower lobar bronchus

Table 2: Bronchoscopic findings of bronchial anthracofibrosis $(n=104)$

underwent diagnostic bronchoscopy and Chung et al. [6] reported anthracofibrosis in $3.1 \%$ of patients. According to the findings of our study, among patients who underwent routine diagnostic bronchoscopy the prevalence of anthracosis and anthracofibrosis were 2.8 and $3.8 \%$ respectively.

Although the mechanisms that underlie the formation of anthracofibrosis are unclear, it has been shown that long term exposure to biomass is one of the most important risk factors [16-19]. Cigarette smoke, air pollution, and mixed mineral dust are described among the other environmental factors known to cause anthracosis $[3,4,20,21]$. Torun et al. [18] described 27 patients with anthracofibrosis who had a history of prolonged exposure to wood smoke, and no occupational history of exposure to coal. A correlation between exposure to biomass fuel and anthracosis is reported by Sandoval et al. [4]. In our study, $53 \%$ of the patients with anhtracosis were non-smokers whereas only $38 \%$ had occupational mineral dust exposure. In their study, Sigari $\mathrm{N}$ et al. [22] reported that more than $93 \%$ of all the female patients were housewives who lived in rural areas, and as many as $40 \%$ of males were farmers who inhabited rural areas. In our study we found that the affected female/male ratio was nearly equal and the $45 \%$ of affected females were housewives most of whom lived in rural areas. In some reports, anthracofibrosis is known as a disease of elderly women who are exposed to biomass fuel. The preponderance of female patients with anthracosis in other reports may be explained by the exposure of women to wood smoke. The finding of only $38 \%$ of mineral dust exposure among our patients may support the hypothesis that factors other than occupation have a role in the pathogenesis of these conditions.

In the study of Sigiari et al. [22], bilateral bronchial involvement was found in $62.5 \%$ of the patients on bronchoscopic examination and bronchial narrowing and obstruction was observed in $37.4 \%$ of the patients. Young $\mathrm{KH}$ et al. [8] reported that among 54 bronchial anthracofibrosis cases, the right middle lobe bronchus was the most commonly involved site (63\%) on bronchoscopy. In the same study while single-site involvement was noted in $48 \%$ of patients multiple site involvement was seen in $52 \%$. In our study, the left upper lobe bronchus was the most commonly involved site on bronchoscopy. Single site involvement was noted in $32(30.8 \%)$ of anthracofibrosis and in $33(31.7 \%)$ of anthracosis patients. Torun et al. [18] showed that the most common bronchoscopic findings were anthracosis and bronchial narrowing among their patients noted mostly at right upper lobe followed by right middle lobe. Wynn et al. [15] reported that there was a predilection for right middle lobe bronchus leading to lobar collapse mimicking cancer.

Anthracofibrosis is a bronchoscopic finding showing dark anthracotic pigmentation on the bronchial mucosa in conjunction with bronchial narrowing or obliteration. Most patients are elderly women who usually are present with cough, sputum and dyspnea. Because of their age and segmental or lobar atelectasis on chest radiographs, bronchoscopy and chest $\mathrm{CT}$ are usually performed to exclude bronchogenic carcinoma. On CT a segmental collapse distal to the involved bronchi was the most common finding. The right middle lobe was the most frequently involved lobe (51\%). Bronchial narrowing was noted in $80 \%$ of patients. In our study, consolidation was the most common finding on CT scan. Consolidation was unilateral in 41 (39.4\%) of patients and bilateral in $18(17.3 \%)$ of them.

The finding in our study that majority of anthracofibrosis patients were from Kastamonu; a city in northern part of Turkey having costal borders with Black Sea was striking. The heavily forested geographical feature of Black Sea region and widespread use of wood for heating or as fuel in the kitchen may be the explanations for high rates of biomass exposure living in this part of Turkey. 
Citation: Comert SS, Dogan C, Caglayan B, Fidan A, Kiral N, et al. (2012) The Demographic, Clinical, Radiographic and Bronchoscopic Evaluation of Anthracosis and Anthracofibrosis Cases. J Pulmonar Respirat Med 2:119. doi:10.4172/2161-105X.1000119

We could not find any literature data about the geographical distribution of anthracofibrosis cases from Turkey. We propose that these patients with anthracosis from that region of Turkey should be evaluated in another prospective trial.

In conclusion, among patients who undergo routine bronchoscopy, anthracosis and anthracofibrosis are diagnosis that may easily be missed or findings may be attributed to other causes. Thorough clinical evaluation and close follow-up of patients are required, since tuberculosis, pneumonia and malignancy may be associated with bronchial anthracofibrosis. Large scale,country-wide studies should be conducted for the determination of epidemiological data of bronchial anthracosis and anthracofibrosis in our country in which a high rate of biomass exposure is found.

\section{Acknowledgments}

There is not any contributions made by colleagues other than the authors.

The authors have no conflicts of interest to disclose. There is no grant support received for this study.

\section{References}

1. Bircan HA, Bircan S, Oztürk O, Ozyurt S, Sahin U, et al. (2007) Mediastinal tuberculous lymphadenitis with anthracosis as a cause of vocal cord paralysis. Tuberk Toraks 55: 409-413.

2. Alois D (1998) Pneumoconioses: Definition. In: Stellman JM (ed), Encyclopedia of Occupational Health and Safety. Geneva: International Labour Organization :10-32.

3. Castranova V, Vallyathan V (2000) Silicosis and coal workers' pneumoconiosis. Environ Health Perspect 108 675-684.

4. Grobbelaar JP, Bateman ED (1991) Hut lung: a domestically acquired pneumoconiosis of mixed aetiology in rural women. Thorax 46: 334-340.

5. Gold JA, Jagirdar J, Hay JG, Addrizzo-Harris DJ, Naidich DP, et al. (2000) Hut lung. A domestically acquired particulate lung disease. Medicine (Baltimore) 79: $310-317$

6. Chung MP, Lee KS, Han J, Kim H, Rhee CH, et al. (1998) Bronchial stenosis due to anthracofibrosis. Chest 113: 344-350.

7. Kala J, Sahay S, Shah A (2008) Bronchial anthracofibrosis and tuberculosis presenting as a middle lobe syndrome. Prim Care Respir J 17: 51-55.
8. Kim HY, Im JG, Goo JM, Kim JY, Han SK, et al. (2000) Bronchial anthracofibrosis (inflammatory bronchial stenosis with anthracotic pigmentation): CT findings. AJR Am J Roentgenol 174: 523-527.

9. Long R, Wong E, Barrie J (2005) Bronchial anthracofibrosis and tuberculosis: CT features before and after treatment. AJR Am J Roentgenol 184: S33-36.

10. Park HJ, Park SH, Im SA, Kim YK, Lee KY (2008) CT differentiation of anthracofibrosis from endobronchial tuberculosis. AJR Am J Roentgenol 191: 247-251.

11. Choe HS, Lee IJ, Lee $Y$ (2004) The CT findings of bronchial anthracofibrosis: comparison of cases with or without active tuberculosis. J Korean Radiol Soc 50: $109-114$

12. Moon WK, Im JG, Yeon KM, Han MC (1997) Tuberculosis of the central airways: CT findings of active and fibrotic disease. AJR Am J Roentgenol 169: 649-653.

13. Kim Y, Lee KS, Yoon JH, Chung MP, Kim H, et al. (1997) Tuberculosis of the trachea and main bronchi: CT findings in 17 patients. AJR Am J Roentgenol 168: 1051-1056.

14. Mirsadraee M, Saeedi $P$ (2005) Anthracosis of lung: evaluation of potential underlying causes. J Bronchology Interv Pulmonol 12: 84-87.

15. Wynn GJ, Turkington PM, O'Driscoll BR (2008) Anthracofibrosis, bronchial stenosis with overlying anthracotic mucosa: possibly a new occupational lung disorder: a series of seven cases From one UK hospital. Chest 134: 1069-1073.

16. Amoli K (1998) Bronchopulmonary disease in Iranian housewives chronically exposed to indoor smoke. Eur Respir J 11: 659-663.

17. Sandoval J, Salas J, Martinez-Guerra ML, Gómez A, Martinez C, et al. (1993 Pulmonary arterial hypertension and cor pulmonale associated with chronic domestic woodsmoke inhalation. Chest 103: 12-20.

18. Torun T, Tahaoglu K, Ozmen I, Sevim T, Atac G, et al. (2007) The role of surgery and fluoroquinolones in the treatment of multidrug-resistant tuberculosis. Int $J$ Tuberc Lung Dis 11: 979-985.

19. Kim YJ, Jung CY, Shin HW, Lee BK (2009) Biomass smoke induced bronchia anthracofibrosis: presenting features and clinical course. Respir Med 103: 757 765 .

20. Boespflug MD, Bourliere-Najean B, Panuel M, Petit P, Doucet V, et al. (1999) Pulmonary anthracosis in children. Eur Radiol 9: 485-486.

21. Naccache JM, Monnet I, Nunes H, Billon-Galland MA, Pairon JC, et al. (2008) Anthracofibrosis attributed to mixed mineral dust exposure: report of three cases. Thorax 63: 655-657.

22. Sigari N, Mohammadi S (2009) Anthracosis and anthracofibrosis. Saudi Med J 30: 1063-1066. 